\title{
How Do Broca's Aphasics Comprehend Chinese Passive BEI?
}

\author{
Yueyuan $\mathrm{Li}^{1}$, Yuehan $\mathrm{Wu}^{2}$, Xinhui Zhang ${ }^{3 *}$, Zhuoyan Zhang ${ }^{4}$ \\ ${ }^{1}$ Department of Language and Linguistic Science, University of York, York, YO10 5DD, United Kingdom \\ ${ }^{2}$ School of Foreign Languages and Cultures, Nanjing Normal University, Nanjing, Jiangsu 210023, China \\ ${ }^{3}$ School of Arts, Languages and Cultures, The University of Manchester, Manchester, M13 9PL, United Kingdom. \\ ${ }^{4}$ Canada British Columbia Hefei No.1 Middle school, 2356 Xizang Road, Hefei, Anhui 230601, China. \\ *kellyannezoeng@gmail.com.
}

\begin{abstract}
In recent years, there are many studies concentrating on the syntactic comprehensive ability of patients with Broca's aphasia who are all native English speakers. Among them, the mechanism of how patients comprehend passive sentences is concerned by many researchers. Contrastively, there are few studies on how native Chinese speakers with Broca's aphasia comprehend passive sentences. Based on relative theories and studies, such as Trace Deletion Hypothesis (TDH), Double Dependency Hypothesis (DDH) and the eye-tracking experiment aiming at English agrammatic patients, this paper focuses on one type of the Chinese passive sentence, sentence passive bei, raises a proposal that constructs a research scheme for Chinese agrammatic patients, puts forward a series of hypothetical results, and based on current solid theories, carries out various explanations for possible results.
\end{abstract}

Keywords: Broca's aphasia, agrammatic patients, Chinese passive bei, gap, eye-tracking, TDH, DDH

\section{INTRODUCTION: BROCA'S APHASICS' SYNTACTIC PROBLEMS \& PASSIVE SENTENCES}

\subsection{Broca's aphasics' syntactic problems}

At early stages, the impairment of comprehension of Broca's aphasics was not a focus of major research. In contrast, the speech production problem of Broca's aphasics was widely studied since Broca's aphasia was initially thought to only lead to the speech production problem. They proposed that there were two completely different systems that controled the speech production and comprehension respectively [1]. As experiments of this field were developed, this proposal was proved to be erroneous. The impairment of Broca's aphasia might be parallel in both speech production and comprehension [2]. According to the study of Ferreira et al. on speech production in 1996, people were sensitive to the syntactic complexity of sentences in both speaking and listening [3]. Additionally, the processing time that they spoke the syntactically complex sentences were longer than syntactically simple sentences [3]. Thus, the production of complex spoken messages involves the syntactic ability of people. Furthermore, in 1976, Caramazza and Zurif attested that Broca's aphasics could not syntactically comprehend the syntactically complex sentences (i.e., semantically reversible sentences) [4]. Besides, Cooke et al. stated: "one of the most important feature of sentence comprehension is its reliance on the information of syntactically-licensed long-distance dependency relations" [5]. More specifically, the processing difficulty of syntactically complex sentences was due to the wrong judgement of the thematic role of a sentence that brought by the syntactically long-distance movement [5]. Thus, syntactic processing ability is the main feature of Broca's area.

\subsection{English Broca's aphasics' comprehension of passive sentences}

In 1975, Gleason et al. designed a Story Completion Test [6]. In this test, they gave the patients with Broca's aphasia several sentences creating a highly structured linguistic environment and asked them to complete the tiny story that was suitable for the environment [6]. During the sentence production, the researchers would see whether the subjects could produce sentences containing the syntactic structure they wanted to elicit. In the test, 14 
story completion stimuli were raised and ranked from the easiest to the hardest. And the passive structure was in the 10th position [6]. This means the passive voice may be challenging for Broca's aphasics and if we want to do some research on the syntactic comprehension of Broca's aphasics, we can pay attention to the passive voice. Besides, we also notice that there are abundant studies about how aphasics whose mother tongue is English comprehend and process passive voice, but similar studies focusing on aphasics whose mother tongue is Chinese are rare. Therefore, it is meaningful to do some research on how Chinese Broca's aphasics comprehend Bei passive in Chinese.

\section{THEORETICAL BACKGROUND}

\subsection{Based on English}

\subsubsection{Gap filling}

As Cooke et al. stated: "movement of complex sentence structures leaves an abstract, phonetically unrealized placeholder in the vacated position or gap" [5]. In experiments, the sentence processing was realtime, which meant the link between the displaced element and the gap was formed in real-time as well [5]. Thus, the meaning of displaced element would be processed in the position 2 at first, then the meaning would be reprocessed in the position 1 which is indexed by the trace. This operation is gap filling.

(1) [The boy (position 2)] that the girl chased (gap (position 1)) was lost.

Additionally, "gap filling is fast acting, and prima facie, dependent up short-term memory" [5]. The longdistance gap filling, therefore, may account for the difficulty of the comprehension of syntactically complex sentences.

\subsubsection{Trace Deletion Hypothesis}

Trace Deletion Hypothesis (TDH) was put forward by Grodzinsky [2,7]. The theory has strong theoretical foundations, including the Trace Theory, the thetacriterion, the theory of Case, and the transformational rule of Move-alpha $[1,8,9]$. Trace Theory believed that when a NP is moved from one place to another, a trace will be left in its original place [8]. The trace and the moved NP share the same coindexation. The trace is marked as a italic t, with grammatical function but no phonetic overtness [1]. In Language Deficits and the Theory of Syntax (1986), Grodzinsky mentioned the last three theories and explained them in detail [1]. The thetacriterion ensures the compatibility of assigners and assignees in the sentence [8]. Usually, the verb is the assigner and the NP is the assignee. Basically, the relation between each NP and the $\theta$-role (thematic role) must be one-to-one correspondence. The theta roles are semantic functions and the two necessary roles to introduce for this article is AGENT (i.e. actor) and THEME (i.e. acted upon) [1]. The theory of Case is another criterion carried out to assure the grammaticity of sentence structure $[8,9]$. Its core is: "Every phonetically realized NP must have Case" [1]. The transformational rule of Move-alpha is considered as the literal expression of the deep structure because it reflects the mapping between the deep structure and the surface structure. Besides, it mentions that a trace is left in the vacated position caused by the moved element, and it links to the current position where the moved element is. To illustrate these theories more clearly, an example is followed. In passive sentence (2), "the thief" is regarded as moved from the place after "caught" and thus there is a trace left, as shown in (3). "the thief" and $t$ share the same index, which means that they are coindexed, as they both refer to the same NP.

(2) The thief was caught.

(3) [The thief $]_{\mathrm{i}}$ was caught $t_{\mathrm{i}}$.

In 1995, Grodzinsky generalized that all the traced are deleted in agrammatism [7]. Accordingly, the patients lose the ability to identify the agent and the theme in one sentence. For example, in sentence (4), the agent is Mary because Mary has the act of action "clean" and the theme is table because table is acted upon, in this case, cleaned. However, for agrammatism, they have difficulty in understanding this passive relation, although they have no problem in understanding active sentence, such as sentence (5).

(4) The table was cleaned by Mary.

(5) Mary cleaned the table.

In 2000, Grodzinsky summarized and revealed the truth related to $\mathrm{TDH}$, which was discovered by observing most Broca's aphasics [2]. There are two points in total: (1) in Broca's aphasics syntactic representation, the traces are deleted; (2) $\theta$-roles assigned according to the linear sequence to the phrases which are not assigned yet, which means that the first NP is assigned the agent.

\subsubsection{Double Dependency Hypothesis and the VP-Internal Subject Hypothesis}

Although the TDH has been proved to have deficiency, it gives an insight to the Double Dependency Hypothesis (DDH) raised by Mauner, Fromkin, and Cornell in 1993 [10]. They suggested that it was not the disability to assign the correct the thematic roles, but the disability to distinguish the traces related to the NPs that led to mistakes in agrammatism. After revision, Mauner et al. summarized DDH in Comprehension and Acceptability Judgements in Agrammatism: Disruptions in the Syntax of Referential Dependency as followed: 
a. "The deficit underlying asyntactic comprehension affects the processing of syntactic referential dependencies, and

b. When there is only one such dependency the resulting syntactic representation, although abnormal, is not ambiguous, but when there are two such dependencies the resulting semantically ambiguous."

According to DDH, the key that causes comprehension ambiguity is the double dependency in one sentence. In object-extracted sentence and passive sentences, there are two dependencies. For example, there is a passive sentence (6) which has two dependencies. The deep structure is shown in two ways in (7a) and (7b). -en does not represent part of the tense reflection of "eat" in this case, but means the past participial morpheme [10]. In either analysis, there are two thematic dependencies, which are "eat + en" and "a boy", and "an apple" and the trace. For Broca's aphasics and other patients with agrammatism, they may confused about who ate the apple and which subject is eaten. It is possible that they may consider that the apple is the subject of the action "eat" and the boy was the object that was eaten.

(6) An apple was eaten by a boy.

(7) (a) $[\text { An apple }]_{\mathrm{i}}$ was eat $+\mathrm{en}_{\mathrm{j}} t_{\mathrm{i}}$ by [a boy $]_{\mathrm{j}}$.

(b) $[\text { An apple }]_{\mathrm{i}}$ was $\mathrm{e}_{\mathrm{j}}$ eat + en $t_{\mathrm{i}}$ by [a boy $]_{\mathrm{j}}$.

So far, the key to DDH, the VP-Internal Subject Hypothesis is not discussed yet. It suggests that within a $\mathrm{VP}$, all the $\theta$-roles are assigned by a verb [10]. Some linguists further concluded that in the VP, subjects bind the trace. For example, sentence (8b) further explains the bound trace inside VP of sentence (8a). This example also indicates that even the simple sentence structure as Matter exists can be analyzed involving trace.

(8) (a) A dog is running after a boy.

(b) $[\mathrm{A} \mathrm{dog}]_{\mathrm{i}}$ is $\left[t_{\mathrm{i}}\right.$ running after a boy].

\subsubsection{Agent-first processing}

For agrammatic patients, they have problem in assigning THEME and AGENT in one sentence. Thus, their default strategy was activated and they assign the first NP in the sentence as the AGENT [7]. This strategy is called Default Principle [1]. This is the core of agentfirst processing. Agent-first processing is not a linguistic strategy as it is based on linear sequence of NPs but not their syntactic or semantic roles. The patients are forced to guess the $\theta$-role and perform at chance. This abnormal action contains no trace. In out research proposal, we will assume whether this default strategy functions as well among Chinese patients.
According to our research, the phenomenon of agentfirst processing does exist on Chinese's aphasics when they are comprehending passive sentences. For instance, in 1997, the test report from Wang Dechun, Wu Benhu, and Wang Delin showed that Chinese Broca's patients enrolling in their test could not understand the meaning of passive sentence with bei like "The apple was eaten by the child." and wondered how the apple could eat the child [11]. The analysis of this pheonomenom is shown in figure 1.

[苹果被 (bei) 小孩吃了]

The apple was eaten by the child.

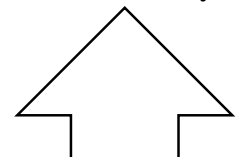

Chinese Broca's patients enrolling in the test recognized the first NP apple as the AGENT which leads to the difficulty in comprehending this sentence.

Figure 1 Analysis of the agent-first processing phenomenon in Wang et al.'s test.

In the sentence above, since the NP apple appears in front of the NP child in terms of the position in the sentence, Chinese Broca's patients assign apple (the first NP) as the AGENT which leads to the misunderstanding of "apple eat the child." We infer this unique phenomenon of Chinese Broca's patients' comprehension about Chinese passive sentence exists because of the different structures of Chinese passive sentences compared with other languages and the special characteristics of the word bei. Therefore, we then do some further research on Chinese passive sentence and the word bei.

\subsection{Based on Chinese}

\subsubsection{Chinese passive bei with gaps}

In syntax, bei in most Chinese passive sentences is considered as a verb that takes a clausal complement [12]

(9)

(a) Zhangsan bei Lisi da-le. Zhangsan PASS Lisi hit-ASP. 'Zhangsan was hit by Lisi'.

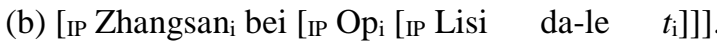
Zhangsan PASS HLisi hit-ASP.

(9b) represents the widely accepted internal structure of the bei passive sentences in Mandarin Chinese. The embedded clausal complement of this sentence contains a 
gap. More specifically, "bei takes an IP complement, the object argument of this embedded IP adjoins to the IP in the form of an empty operator" [12]. However, bei passive that contain no apparent gap is available in Mandarin Chinese as well.

\subsubsection{Chinese passive bei with no apparent gap}

Chinese passive BEI with no apparent gap is related to DDH and the VP-Internal Subject Hypothesis mentioned above. Sentence (10), further analyzed by sentence (11) is a sentence with no apparent gap. Inside $\mathrm{VP}$, there is a subject which as represented by $t$. According to Lin, the operator is the "outer object" of the VP [12]. The operator and the trace are coreferential. There is a gap in (11) because there is a trace appearing in the sentence while it is not apparent. It can be considered that there is only one index in the deep structure and the VP is intact. Thus, there is no apparent gap in this sentence.
(10) Xiaoming
bei
Xiaofang
jie-le
qian.
Xiaoming
PAS
Xiaofang
borrow-ASP
money.
'Xiaoming had Xiaofang borrow [his] money.'
(11) [IP Xiaoming Xiaoming

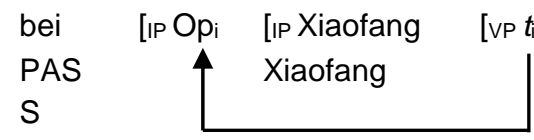
[v'jie-le
borrow-ASP
[NP Proi
Qian]]]]]]
money.

'Xiaoming had Xiaofang borrow [his] money.'

\subsubsection{Chinese passive bei without gaps}

The weak NP is the locus of bei passive sentences. Thus, the property of weak NPs should be introduced at first before the specific analysis of gapless bei passive sentences. In fact, there is an opposite term of weak NPs (i.e., Strong NPs). Weak NPs (e.g., indefinite expressions) can be used in existential sentences, while strong NPs (e.g., definite expressions, proper names) cannot [13]. The definition of existential sentences in Mandarin Chinese is that it follows a structure that is used for the expression of existence of something [14]. The structure of a Mandarin existential sentence consists of three parts (i.e., place + verb + object), as shown in (12). The object must contain weak NPs.

a.

$$
\begin{aligned}
& \text { The Front Part } \\
& \text { (Place) }
\end{aligned}
$$

书包里

Shu bao li

In the bag

'There is a book in the bag.'

b.

$$
\text { 墙上 }
$$

On the wall

'There is a piece of cloth on the wall.'

c.

$\begin{array}{ll}\text { 小河旁边 } & \text { 是 } \\ \text { Xiao he pang bian } & \text { shi } \\ \text { Besides the creck } & \text { is }\end{array}$

\begin{tabular}{|c|c|}
\hline $\begin{array}{c}\text { The Middle Part } \\
\text { (Verb) }\end{array}$ & $\begin{array}{l}\text { The Final Part } \\
\text { (object) }\end{array}$ \\
\hline 有 & 一本书。 \\
\hline you & yi ben shu. \\
\hline is & a book. \\
\hline 挂着 & 一件衣服。 \\
\hline gua zhe & yi jian yi fu. \\
\hline hangs & a piece of cloth \\
\hline & \\
\hline 是 & 一条大马路。 \\
\hline shi & yi tiao da ma lu. \\
\hline & \\
\hline
\end{tabular}$$
\text { 挂着 }
$$

$$
\text { hangs }
$$$$
\text { gua zhe }
$$

In Mandarin Chinese, a bei passive sentence can be gapless if it contains a weak NP in the embedded IP. According to Lin, direct merge and binding of Op to the embedded IP that contains a weak NP is available to produce a bei passive sentence without gap [12]. (a) *Zhangsan bei Lisi da-shang-le meiyige ren.

Zhangsan PASS Lisi hit-wound-ASP every person. 
'(intended) Zhangsan had Lisi hit and wound every person.'

(b) Zhangsan bei Lisi da-shang le liang-ge ren.

Zhangsa PASS Lisi hit-wound-ASP two person.

'Zhangsan had Lisi hit and wound two persons.'

(13a) is ungrammatical since the determiner of 'meiyige ten' (every person) is a strong determiner. Strong NPs cannot syntactically license bei passive sentences with gap [12]. On the contrary, the determiner "liangge" (two) in (13b) is a weak NP. Thus, (13b) is grammatical. The reason why (13a) is ungrammatical is because Zhangsan cannot be the possessor of every people. There is no semantic intersection between Zhangsan and every people.

\section{TESTING PROCEDURE}

\subsection{Participants}

It is intended to set two test groups of participants. One is Aphasics group with 10 patients, and the other is Neurologically Healthy People group, including 10 Neurologically Healthy People. It is required that the average age of all participants is in the range of $50 \pm 5$. Since the patients have diseases, such as cerebral apoplexy or cerebral stroke, mostly in their fifties, it will be much more convenient to find aphasics participants who have Broca's aphasics after suffering from these diseases if we set the participants' age between 45 and 55. Moreover, in order to avoid the influence of gender differences in language comprehension ability, it is designed to include 5 males and 5 females in each test group. What is more, it is also regulated that the participants in both two groups should be all right-handed since we aimed to explore Broca's area in left hemisphere. Additionally, the education years of the participants are in the range of $9 \pm 3$, to make sure all the participants have learned Chinese grammar and can comprehend passive sentence in Chinese before. It is intended to control the education experiences of all the participants between pupil and junior high, as 6 years of education corresponds to the education span of pupil and 12 years of education corresponds to the education span of junior high and senior high students in China. Last but not the least, all of the participants in our test are supposed to be proficient in using mouse to operate and answer on the computer. All these required conditions are presented the table 1 .

Table 1. The conditions for participants in our test to meet

\begin{tabular}{|c|c|c|}
\hline Variables & Aphasics group & $\begin{array}{c}\text { Neurologically } \\
\text { Healthy People } \\
\text { group }\end{array}$ \\
\hline $\begin{array}{c}\text { Amount of } \\
\text { participants }\end{array}$ & 10 & 10 \\
\hline $\begin{array}{c}\text { Amount of male } \\
\text { participants }\end{array}$ & 5 & 5 \\
\hline $\begin{array}{c}\text { Amount of female } \\
\text { participants }\end{array}$ & 5 & 5 \\
\hline Age & $50 \pm 5$ & $50 \pm 5$ \\
\hline Handedness & All right-handed & All right-handed \\
\hline Education years & $9 \pm 3$ & $9 \pm 3$ \\
\hline
\end{tabular}

\subsection{Methods: eye-tracking and its materials}

Inspired by Meyer, Mack and Thompson's research on passive sentence comprehension in Broca's aphasia, we also decide to apply the eye-tracking method to our hypothetical experiment in Chinese Broca's aphasics [15]. According to the three types of Chinese bei structures we have just mentioned, we will select 20 verbs in Chinese which are able to produce all the three bei structures. For each verb, one sentence in active voice and other three sentences using three different types of bei structure are designed. Therefore, we have 40 sentences in total. Then the sentences are organized into four stimulus lists according to the type of the sentence. Each list shows the corresponding structure using the 20 verbs (see Table 2). Considering the effect of spillover, which means the uncompleted processing of the former element will spill over to the next, we predict that the processing task of gap-filling will also be postponed [16]. In order to record the gap-filling process better, we add an unimportant element "de-hua", which express assumptive condition in Chinese, after the key region where the gap appears in the bei passive with gap. To prevent the interference of gender stereotype [i.e., people tend to think the agent of the behavior "da"(hit) is more likely to be a male], we suggest that animals with similar figure and force but of different types, i.e., "mao" (the cat) and "gou" (the dog), can be chosen as the agent and theme.

Table 2. Example sentence list

\begin{tabular}{|c|l|l|l|l|l|}
\hline Verb & A. Active sentence & B. With gaps & $\begin{array}{l}\text { C. With no apparent } \\
\text { gap }\end{array}$ & D. Without gaps \\
\hline 1. Resource & R & $\begin{array}{l}\text { 狗打了猫。 } \\
\text { The dog hit the cat. }\end{array}$ & $\begin{array}{l}\text { 猫被狗打了的话....... } \\
\text { If the cat was hit by }\end{array}$ & $\begin{array}{l}\text { 猫被狗打了头。 } \\
\text { The cat had the dog }\end{array}$ & $\begin{array}{l}\text { Tr被狗打了一下。 } \\
\text { The cat was hit by the dog according to Lin, }\end{array}$ \\
\hline
\end{tabular}




\begin{tabular}{|c|c|c|c|c|c|}
\hline $\begin{array}{l}\text { Da } \\
\text { hit }\end{array}$ & & the $\operatorname{dog} \ldots$ & hit the head. & once. & 2009 \\
\hline \begin{tabular}{|l} 
2. 称 \\
Tian \\
lick \\
\end{tabular} & $\begin{array}{l}\text { 狗舔了猫。 } \\
\text { The dog licked the } \\
\text { cat. }\end{array}$ & $\begin{array}{l}\text { 猫被狗舔了的话...... } \\
\text { If the cat was licked } \\
\text { by the dog... }\end{array}$ & $\begin{array}{l}\text { 猫被狗舔了脸。 } \\
\text { The cat had the dog } \\
\text { lick the face. }\end{array}$ & $\begin{array}{l}\text { 猫被狗舔了一下。 } \\
\text { If the cat was licked by } \\
\text { the dog once. }\end{array}$ & Original \\
\hline \begin{tabular}{|l} 
3. 偷 \\
Tou \\
steal
\end{tabular} & $\begin{array}{l}\text { 狗偷了猫。 } \\
\text { The dog stole the } \\
\text { cat. }\end{array}$ & $\begin{array}{l}\text { 猫被狗偷了的话...... } \\
\text { If the cat was stolen } \\
\text { by the dog... }\end{array}$ & $\begin{array}{l}\text { 猫被狗偷了肉。 } \\
\text { The cat had the dog } \\
\text { steal the meat. }\end{array}$ & $\begin{array}{l}\text { 猫被狗偷了一次。 } \\
\text { The cat was stolen by the } \\
\text { dog once. }\end{array}$ & $\begin{array}{l}\text { Modified } \\
\text { according to Lin, } \\
2009\end{array}$ \\
\hline \multicolumn{6}{|l|}{ Other verbs } \\
\hline $\begin{array}{l}\quad 4 . \quad \text { 踹 } \\
\text { Chuai } \\
\text { kick }\end{array}$ & $\begin{array}{l}\text { 5. 捆 } \\
\text { Kun } \\
\text { tie }\end{array}$ & $\begin{array}{l}\text { 6. 抓 } \\
\text { Zhua } \\
\text { grab }\end{array}$ & $\begin{array}{l}\quad 7 . \quad \text { 夸 } \\
\text { Kua } \\
\text { prize }\end{array}$ & $\begin{array}{l}\text { 8. 挤 } \\
\text { Ji } \\
\text { crowd }\end{array}$ & $\begin{array}{ll} & 9 . \quad \text { 拉 } \\
\text { La } & \\
\text { pull } & \end{array}$ \\
\hline $\begin{array}{l}\text { 10. 摸 } \\
\text { Mo } \\
\text { touch }\end{array}$ & $\begin{array}{l}\text { 11. 咬 } \\
\text { Yao } \\
\text { bite }\end{array}$ & $\begin{array}{l}\text { 12. 亲 } \\
\text { Qin } \\
\text { kiss }\end{array}$ & $\begin{array}{l}\text { 13. 骂 } \\
\text { Ma } \\
\text { scold }\end{array}$ & $\begin{array}{l}\quad 14 . \text { 撞 } \\
\text { Zhuang } \\
\text { collide }\end{array}$ & $\begin{array}{l}\text { 15. 翟 } \\
\text { Chuo } \\
\text { poke }\end{array}$ \\
\hline $\begin{array}{l}\quad 16 . \text { 敲 } \\
\text { Qiao } \\
\text { Knock }\end{array}$ & $\begin{array}{l}\text { 17. 揪 } \\
\text { Jiu } \\
\text { seize, hold tight }\end{array}$ & $\begin{array}{l}\text { 18. 抱 } \\
\text { Bao } \\
\text { hug }\end{array}$ & $\begin{array}{l}\text { 19. 叫 } \\
\text { Jiao } \\
\text { shout }\end{array}$ & $\begin{array}{l}\text { 20. 推 } \\
\text { Tui } \\
\text { push }\end{array}$ & \\
\hline
\end{tabular}

Besides, the agent might be predictable if we used the same animal all the time. Therefore, when a verb is repeated in the second half of the experiment, the agent and the theme will be reversed [15]. Also, it is worth paying attention to the option of weak-NPs (see the analysis in 2.1.2), when we design sentences with gapless bei. For each verb, two pictures will be designed (see Fig. 1 for example). One picture shows that an agent exerts an action on a theme, i.e., Mao bei Gou da-le. (The cat was hit by the dog.), while on the second pictures the agent and theme will be reversed. i.e., Gou bei Mao da-le. (The dog was hit by the cat.) The location of the drawings corresponding to the target sentence will be counterbalanced across trials [15]. In addition, it is difficult to use pictures to present some weak NP in Chinese like “一下” (once), so we propose that we can change the static pictures into animation or GIF to present the action like Gou hit Mao once. All picture stimuli will be tested by healthy young volunteers to make sure that they are clear [15].
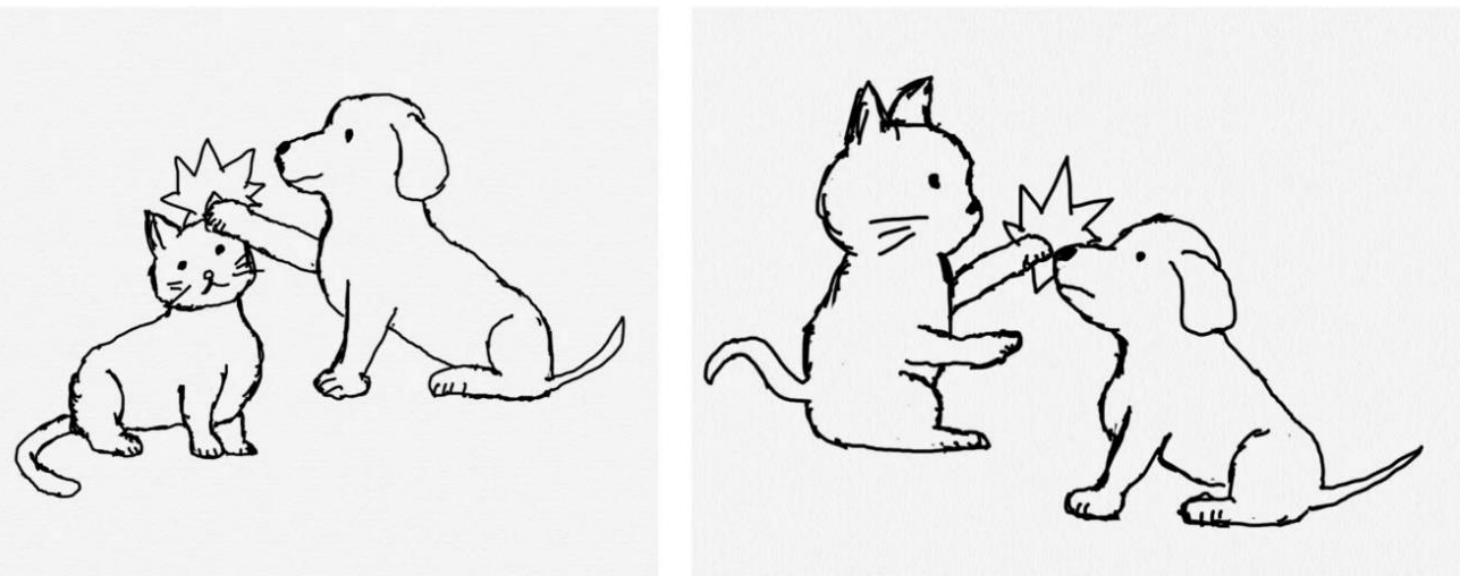

Figure 2 Example of the picture group from a trial. The verb used in the group is "da" (hit). 


\subsection{Procedures}

1) All participants will see the relevant pictures for the selected verbs on the computer screen and the corresponding verb for $5 \mathrm{~s}$. Meanwhile, we ask them to read these verbs silently and raise questions about verbs they do not understand [15].

2) Following the familiarization procedure, instructions about the experiment will be given. The participants will see two pictures when they hear a sentence for the trial. Then they should use a mouse to click on the picture that they think correctly depicts the sentence [15].

3) After that, the participants will be brought to a dimly-lit room with the eye-tracker. At first, a fixation cross is presented on the screen for 3 seconds and when it disappears, two pictures appear on the screen. 500 milliseconds later, the subjects will hear the sentence and see the relevant group of two pictures. After they use the mouse to click on one of the pictures, the system will automatically enter the next trial [15].

\subsection{Data analysis}

Firstly, the sentences will be divided into the following five regions (see table 3 ). In each time region, the proportions of fixations on the target and distractor pictures will be calculated, and the average fixation proportions will be computed for different types of sentences [15]. If the participants' eyes are fixed on the same position for 100 milliseconds, it will be considered as a fixation. Then a target advantage score in each region of the sentence will be calculated by subtracting the average fixation proportion of the distractor picture from the average fixation proportion of the target picture [15]. Besides, we will submit the target advantage scores to a one-sample $t$ test with a comparison value of 0 , which equates to chance performance [15].

If patients with Broca's aphasia are also able to finish the gap-filling in the passive with agility and accuracy, we expect a positive target advantage, which is represented by an upward bar, to emerge in the region after the gap. That means if the agrammatics can perform the gapfilling, positive target advantage is expected to appear in region 5 for bei passive with gap, while in region 4 and 5 for bei passive with no apparent gap. For bei passive without gap, we predict that no significant target advantage score will appear.

As we can see in the hypothetical graphs (i.e. Figure 3 ), the bar in shallow color, which represents the healthy participants, is upwards. It shows that the healthy participants can finish the gap-filling in the bei passive with gap, while the bar in deep color, which represents the Broca's aphasics, is insignificant. It shows that the patients cannot do gap-filling in the passive sentence.

Table 3. Five regions that sentences divided into

\begin{tabular}{|c|c|c|c|c|c|}
\hline & Region 1 & Region 2 & Region 3 & Region 4 & Region 5 \\
\hline \multirow[t]{2}{*}{ Active } & Gou & da-le & Mao & & \\
\hline & The dog & hit & the cat. & & \\
\hline \multirow{2}{*}{$\begin{array}{l}\text { bei passive } \\
\text { with gap }\end{array}$} & Mao & bei & Gou & da-le & de-hua \\
\hline & If the cat & was hit & by the dog. & & \\
\hline \multirow[t]{2}{*}{$\begin{array}{l}\text { bei passive } \\
\text { with no } \\
\text { apparent gap }\end{array}$} & Mao & bei & Gou & da-le & tou \\
\hline & The cat & had & the dog & hit & the head. \\
\hline \multirow[t]{2}{*}{$\begin{array}{l}\text { bei passive } \\
\text { without gap }\end{array}$} & Mao & bei & Gou & da-le & yi-xia \\
\hline & The cat & was hit & by the dog & & once. \\
\hline
\end{tabular}

\section{EXPECTED RESULTS AND HYPOTHESIS FOR EXPLANATION}

All the graphs in this section are the expected results which means that they are not actual reaction of patients but the investigators' prediction. The analysis of the expected results is divided into three sub-sections to echo the three types of Chinese passive bei sentence.

\subsection{Chinese passive bei with gaps}

There are two expected results for Chinese passive bei with gaps. The first one is that the patients perform the same as the healthy participants. As shown in Figure 3, the patients and the healthy participants both have obvious positive bars in region 5 before which the gap appears. This figure indicates that Broca's aphasics can deal with Chinese passive bei with gaps as well as healthy people. Although the positive data may be lower than that of healthy people, this does not influence that they can react correctly. 
The other prediction is that the Broca's aphasics cannot detect the place of the gap and consequently, there is not obvious positive bar in region 5 as shown in figure 4. This expected result indicates that the patients cannot comprehend Chinese passive bei with gaps. The three possible explanations are that: (1) the traces of patients are deleted, according to TDH, and thus they cannot judge the rightness of the picture; (2) the patients are confused about which one is the agent. According to agent-first processing, they are guessing the NP's theta role and their bars do not reveal obvious difference with one another as they cannot pick the right picture; (3) there are chaos with double dependencies among patients, according to DDH. Thus, the patients cannot detect the gap and cannot choose the right picture.

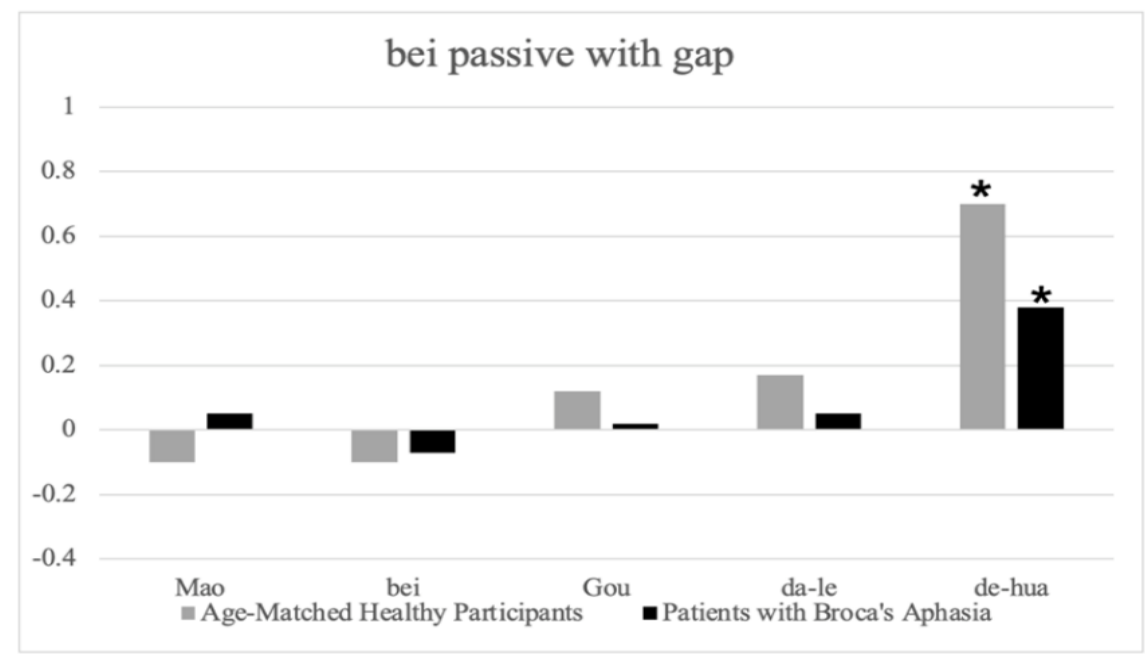

Figure 3 Average target advantage for bei passive with gap successfully filled by both the healthy participants and the patients. Asterisks indicate an evident positive target advantage, i.e., tendency to focus on the correct (positive) picture.

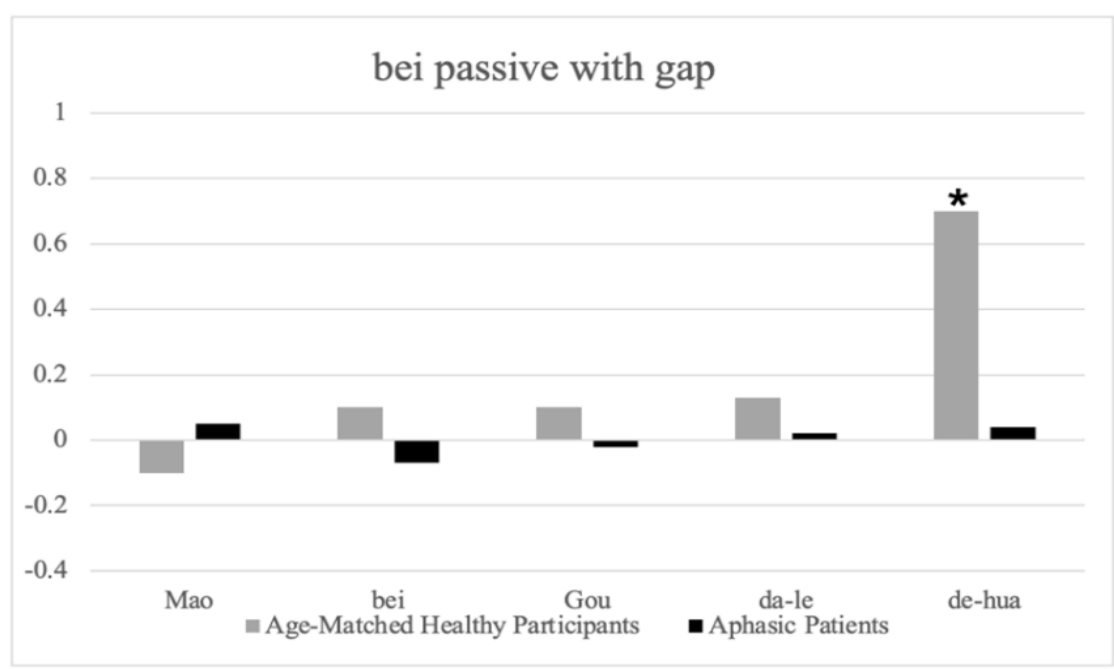

Figure 4 Average target advantage for bei passive with gap filled only by the healthy participants. Asterisks indicate an evident positive target advantage, i.e., tendency to focus on the correct (positive) picture.

\subsection{Chinese passive bei with no apparent gap}

There are three expected results for Chinese passive be $i$ with no apparent gap. The first one is shown in figure 5 , where the patients also have positive results in region 4 and 5, same as healthy participants. This would reveal that Broca's aphasics can comprehend Chinese passive $b e i$ with no apparent gap without difficulties.
The second prediction is that Broca's aphasics have problems in comprehending Chinese passive bei with no apparent gap. As shown in figure 6, patients show no obvious positive results in all the five regions, which means that they cannot choose the right picture and detect the unapparent gap. The four possible explanations behind this phenomenon are that: (1) the traces of patients are deleted, according to $\mathrm{TDH}$, and thus the patients cannot judge the rightness of the picture; (2) the patients 
are struggling with deciding which one is the agent, according to agent-first processing; (3) there are chaos with double dependencies among patients, according to DDH. Thus, the patients cannot detect the gap and cannot choose the right picture; (4) patients have problem in pronoun coreference. As in Chinese, pronoun is deleted in some contexts and interlocutors can still catch up with others' meaning. However, for Broca's aphasics who may have pronoun coreference problems, they may not even notice there is pronoun deletion and thus cannot comprehend the passive sentence. In this case, they would hesitate about choosing the right picture and their focusing time are similar in all five regions.

The last prediction is that Broca's aphasics would consider the sentence as "Gou bei Mao da-le tou" (i.e. a dog's head was hit by a cat), totally opposite the original meaning (a cat's head was hit by a dog). In this occasion, as shown in figure 7, the bar in regions 4 and 5 are obvious negative as they choose the other picture, namely the wrong one. Different form English, this case is quite probable in Chinese because according to the deep structure of Chinese passive bei with no apparent gap, there is a trace before "da-le" (i.e. hit) and the trace links to the operator which manipulates the possessive pronoun of "tou" (i.e. head). The possible explanations are that: (1) according to $\mathrm{TDH}$, traces exist because patients are aware that someone's head was hit, but if this really appears, this contradict TDH to some extent as the trace is not deleted but wrongly reserved; (2) there are chaos with double dependencies among patients, according to DDH. The patients are sensitive to dependency, but they would fail to link the relation in each dependency right and finally choose the wrong picture.

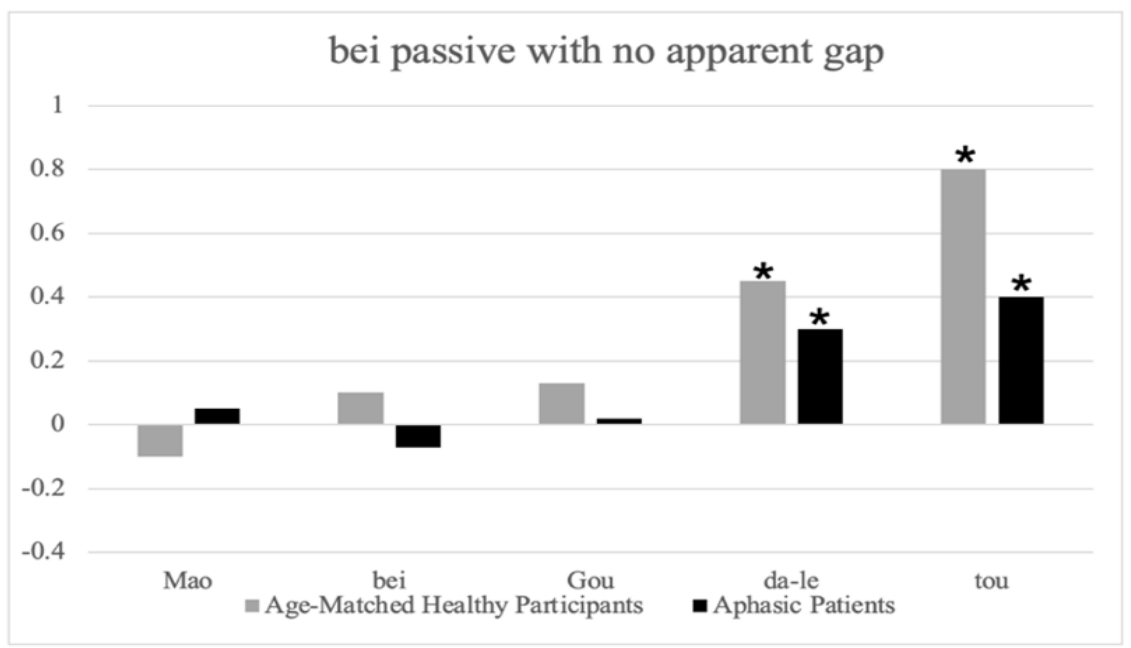

Figure 5 Average target advantage for bei passive with no apparent gap filled by both the healthy participants and the patients. Asterisks indicate an evident positive target advantage, i.e., tendency to focus on the correct (positive) picture.

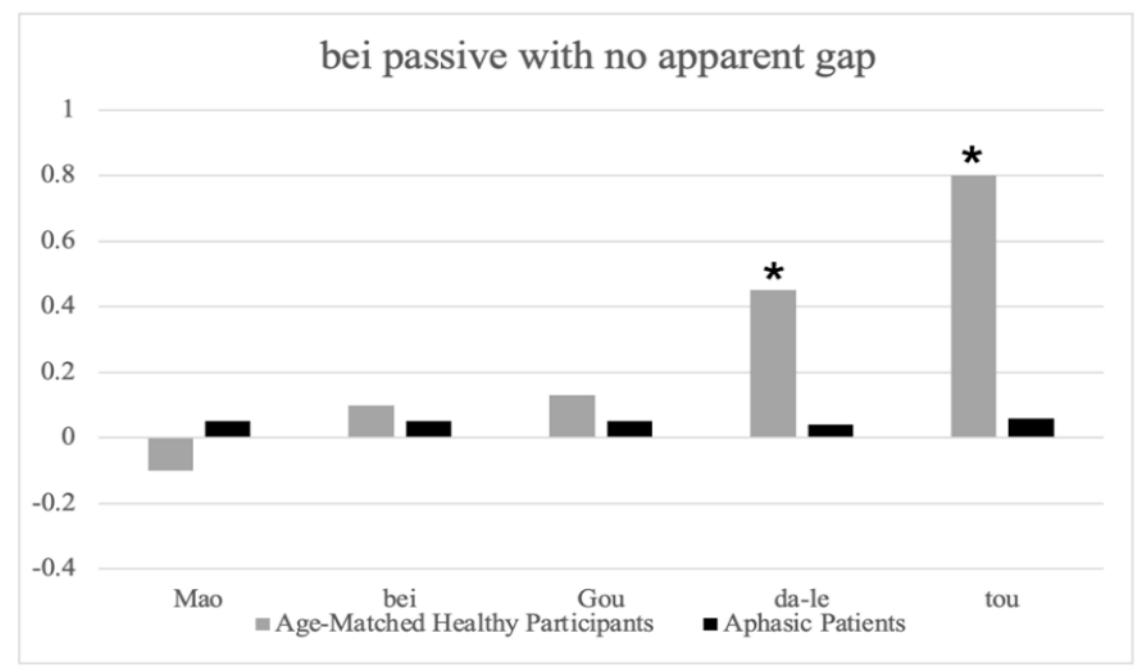

Figure 6 Average target advantage for bei passive with no apparent gap filled only by the healthy participants. Asterisks indicate an evident positive target advantage, i.e., tendency to focus on the correct (positive) picture. 


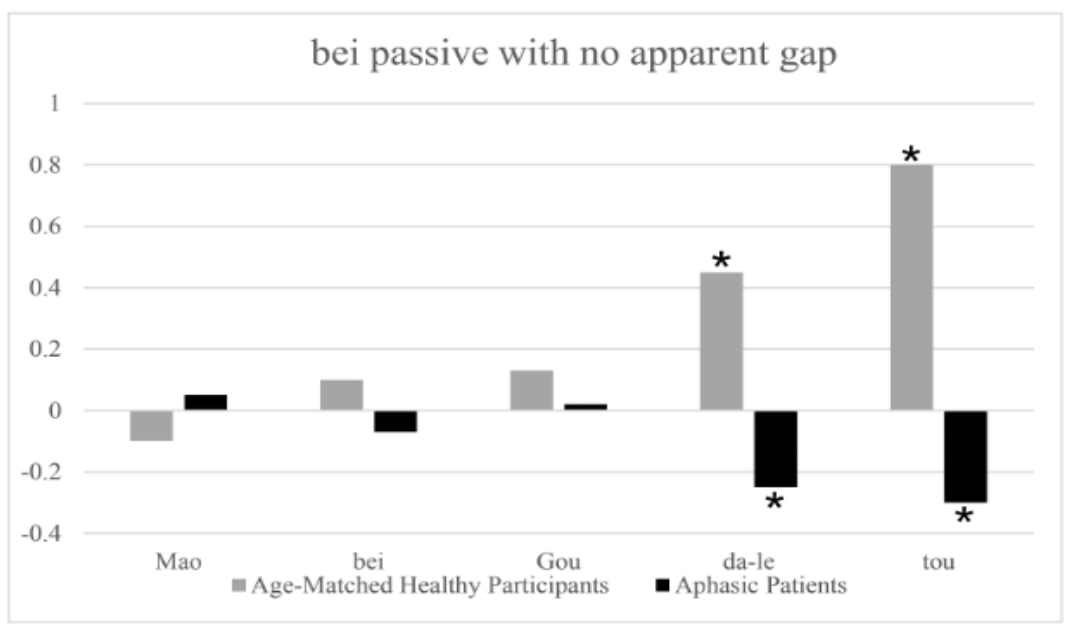

Figure 7 Average target advantage for bei passive with no apparent gap filled only by the healthy participants. Asterisks of grey bars indicate an evident positive target advantage, i.e., tendency to focus on the correct (positive) picture. Asterisks of black bars indicate an evident positive target advantage, i.e., tendency to focus on the wrong (negative) picture.

\subsection{Chinese passive bei with no gap}

There are two expected predictions for Chinese passive bei with no gap. The first one is that the patients can comprehend the sentence the same as healthy participants. As shown in figure 8, there is no gap in the sentence and as a result, there is no trace. Both healthy participants and Broca's aphasics have no obvious positive or negative results.

The other prediction is that the patients cannot comprehend Chinese passive bei with no gap. There are various possibilities of the ways of their comprehension so there is no predicted graph for their miscomprehension. They may start to guess as the sentence nears completion and agent-first processing may not be enough to explain it. Other two possible explanations are that: (1) there are chaos with double dependencies among patients, according to DDH. The patients may identify the two relations wrongly or could not detect that there are even two dependencies; (2) patients have problem in pronoun coreference, leading to the hesitation between two pictures.

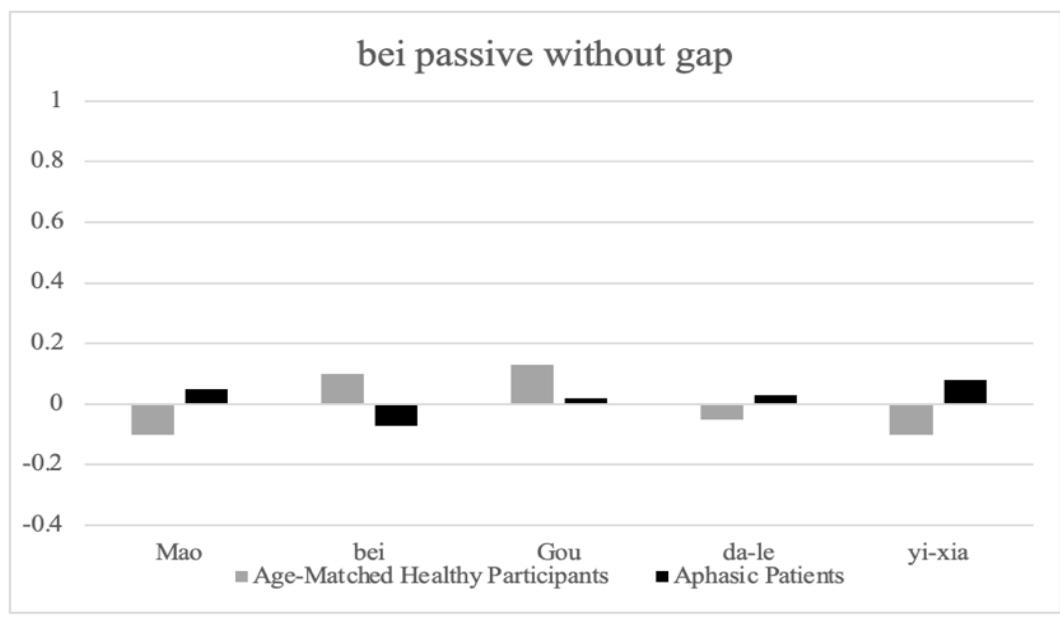

Figure 8 Average target advantage for bei passive without gap filled.

\section{CONCLUSION}

\subsection{The influence of the morpheme "le"}

According to Wang, Zhong and Zhai, "le" (了) is an aspectual morpheme in Chinese. The researchers found that Broca's aphasics whose mother tongue is Chinese performed well in general as they produce the morpheme "le" [17]. Thus, we use "le" in our test sentences firstly because "le" is not difficult for Broca's aphasics, so there is low probability that "le" will disturb the aphasic subjects. Secondly, Chinese native speakers tend to add 
"le" after the verb as long as the behavior happened before the moment when they talk. However, the researchers also mentioned that Broca's aphasics sometimes tend to put "le" at the end of the sentence, which creates ambiguity. Therefore, it is possible that aphasics sometimes have problems with the position "le". Therefore, we hope more research can be conducted to see whether "le" really disturb the production of passive in Chinese.

\subsection{The Gap and working memory}

Furthermore, it has been proved that Broca's aphasia leads to the difficulty of the comprehension of syntactically complex sentences and patients must use their working memory to process such sentences [5]. According to Cui, the syntactic processing of syntactically complex sentences may increase the burden of aphasics' working memory, leading to the barriers to syntactic processing of those aphasics [18]. This leads to an assumption that if aphasics comprehend a sentence without gap, the burden of their working memory may decrease, then they may have a better understanding of syntactically complex sentences.

\section{3. "bei" as a functional word}

The part of speech of the word bei is still a controversial topic in academia. Some experts regarded bei as preposition or verb, while others recognized bei as a functional word. In a nutshell, the word bei is more likely to be a functional word according to the mainstream thoughts in academia and our research. If bei can be recognized as a functional word, then we do some further research on the relationship between Broca's area and functional words comprehension thereby discovering more about how Chinese Broca's aphasics comprehend passive bei:

Cui Gang studied the characteristics of language expressions for Broca's aphasics in Chinese, and showed that Broca's aphasics had serious difficulties in using and comprehending functional words [19].

The proportion of the Chinese aphasia patients in terms of omitting grammatical functional words is higher than that of the English and German aphasia patients found by Bates et al. (1988). Additionally, Bates' study found that English aphasia patients also made more omission errors than those German aphasia patients, probably because of the different characteristics of English, German and Chinese themselves. Among these three Languages, German has the most inflections which is followed by English. While Chinese has the least inflections. It seems to indicate that the proportion for aphasics to make omissions in a certain language is much lower while this kind of language has more inflectional forms.
To sum up, combined the above-mentioned perspectives, it will be a good research direction if we compare Chinese with other languages in terms of functional word structure and Broca's patients' comprehension of passive sentences to discover more unique characteristics of passive bei.

\section{REFERENCES}

[1] Grodzinsky, Y. (1986) Language deficits and the theory of syntax. Brain and language, 27: 135-159.

[2] Grodzinsky, Y. (2000) The neurology of syntax: Language use without Broca's area. Behavioral and brain sciences, 23: 1-21.

[3] Ferreira, F., Henderson, J. M., Anes, M. D., Weeks, P. A., \& McFarlane, D. K. (1996) Effects of lexical frequency and syntactic complexity in spokenlanguage comprehension: Evidence from the auditory moving-window technique. Journal of Experimental Psychology: Learning, Memory, and Cognition, 22: 324.

[4] Caramazza, A. \& Zurif, E. B. (1976) Dissociation of algorithmic and heuristic processes in sentence comprehension: Evidence from aphasia. Brain and Language 3:572-82.

[5] Cooke, A., Zurif, E. B., DeVita, C., Alsop, D., Koenig, P., Detre, J., ... \& Grossman, M. (2001) Neural basis for sentence comprehension: Grammatical and short - term memory components. Human brain mapping, 15: 80-94.

[6] Gleason, J. B., Goodglass, H., Green, E., Ackerman, N., \& Hyde, M. R. (1975) The retrieval of syntax in Broca's aphasia. Brain and Language, 2: 451-454. https://doi.org/10.1016/s0093-934x(75)80083-6

[7] Grodzinsky, Y. (1995) A restrictive theory of agrammatic comprehension. Brain and Language, 50: 27-51. https://doi.org/10.1006/brln.1995.1039

[8] Chomsky, N. (1981) Lectures on Government and Binding. Foris Publications, Dordrecht.

[9] Rouvertert, A., \& Vergnaud, J. R. (1980) Specifying reference to the Subject. Linguistic Inquiry., 11: 97 202.

[10] Mauner, G., Fromkin, V. A., \& Cornell, T. L. (1993) Comprehension and acceptability judgments in agrammatism: Disruptions in the syntax of referential dependency. Brain and Language, 45: 340-370. https://doi.org/10.1006/brln.1993.1050

[11] Wang, H., Zhong, X., \& Zhai, S. (2017) There May Be Tense in the Chinese Language: Empirical Evidence from A Case Study of Chinese Agrammatism. Journal of Beijing International 
Studies University, 1: 52-53. https://doi.org/10.12002/j.bisu.044

[12] Lin, T. H. J. (2009) Licensing "gapless" bei passives. Journal of East Asian Linguistics, 18: 167-177.

[13] Partee, B.H. (2006) Weak Noun Phrases and Existential Sentences. The Structure of Meaning, Lecture 15. http://people.umass.edu/partee/NZ 2006/NZ15\%2 0Weak\%20NPs\%20and\%20Existential\%20Ss.pdf

[14] He, C. (2017) Mastering Existential Sentences in Mandarin.

https://www.digmandarin.com/existentialsentences-mandarin.html

[15] Meyer, A. M., Mack, J. E., \& Thompson, C. K. (2012) Tracking passive sentence comprehension in agrammatic aphasia. Journal of Neurolinguistics, 25:

31-43. https://doi.org/10.1016/j.jneuroling.2011.08.001

[16] Mitchell, D. C. (2018) An Evaluation of SubjectPaced Reading Tasks and Other Methods for Investigating Immediate Processes in Reading 1. In: Kieras, D. E., Just, M. A. (Eds), New Methods in Reading Comprehension Research. Routledge, London. pp. 69-90.

[17] Wang, H., Zhong, X., \& Zhai, S. (2017). There May Be Tense in the Chinese Language: Empirical Evidence from A Case Study of Chinese Agrammatism. Journal of Beijing International Studies University, 1: 52-53. https://doi.org/10.12002/j.bisu.044

[18] Cui, G. (2018). The Theoretical Explanation of the Sentence Comprehension Disorders of Broca's Aphasics. Journal of Beijing International Studies University, 39: 18-29.

[19] Cui, G. (1999). Syntax disorders of patients with Broca's and conductive aphasia. Modern Foreign Languages: 299-307.

[20] Bates, E., Friederici, A., \& Wulfeck, B. (1988). Grammatical morphology in aphasia: A reply to Niemi et al., Cortex, 24: 583-588. 